
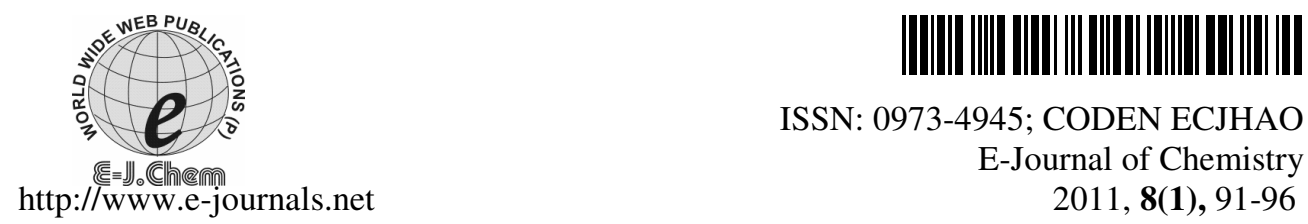

ISSN: 0973-4945; CODEN ECJHAO

E-Journal of Chemistry

2011, 8(1), 91-96

\title{
Preparation and Characterization of Chitosan/Poly(Vinyl Alcohol) Blended Films: Mechanical, Thermal and Surface Investigations
}

\author{
ESAM A. EL-HEFIAN ${ }^{* *}$, MOHAMED MAHMOUD NASEF and \\ ABDUL HAMID YAHAYA ${ }^{\S}$ \\ ${ }^{\S}$ Department of Chemistry, Faculty of Science \\ University of Malaya, 50603 Kuala Lumpur, Malaysia \\ Chemical Engineering Department \\ Faculty of Chemical and Natural Resources Engineering \\ Universiti Teknologi Malaysia, 81310 UTM Skudai, Johor, Malaysia \\ eelhefian@yahoo.com
}

Received 27 April 2010; Accepted 17 June 2010

\begin{abstract}
In this study, blends of chitosan (CS) and polyvinyl alcohol (PVA) (CS/PVA) having various proportions were prepared and characterized by universal mechanical tester, the differential scanning calorimetry (DSC) and contact angle measurements. Studying the mechanical properties of the films showed that blending improved the tensile strength, which increased with increasing PVA content up to $40 \%$ while the elongation\% at break of the blends was decreased compared to that of the pure components. The obtained results of DSC suggested that some interaction between chitosan and PVA mostly took place. Static water contact angle measurements showed an improvement in the wettability of the obtained films.
\end{abstract}

Keywords; Chitosan, Poly(vinyl alcohol), Blended films, Wettability

\section{Introduction}

Polymer blending is a method that is commonly used for providing desirable polymeric materials with combined properties suitable for particular applications ${ }^{1}$. Investigation of blends of chitosan with synthetic and naturally occurring macromolecules has attracted much attention in the recently years in various occasions ${ }^{2-6}$. Blending of chitosan with synthetic polymers is a convenient method for preparation of synthetic biodegradable polymers having versatile properties such as good water absorbance and enhanced mechanical properties while maintaining biodegradability ${ }^{7}$. 
In previous communications, we reported on some of the properties of CS/PVA blended films. This included rheological investigation of blend solutions, FTIR spectral analysis, scanning electron microscopy (SEM), swelling and thermal gravimetric analysis (TGA) of the obtained blended films ${ }^{8,9}$. The aim of the present work is to study the mechanical, the surface (contact angle) and the thermal (DSC) properties of chitosan/PVA blended films at various proportions to establish a clear understanding of the impact of the structure on the properties of the films.

\section{Experimental}

Shrimp source chitosan was purchased from a local company with a deacetylation percentage (DD) of $88.1 \%$ defined by UV method ${ }^{10}$. This chitosan is acid-soluble and whitecolored flakes. PVA Fluka (56-98) with an average molecular weight of $195 \times 10^{3} \mathrm{~g} \mathrm{~mol}^{-1}$ was used in this work. Acetic acid (glacial $100 \%$, pro analysi) was purchased from Merck (Darmstadt, Germany). Ultra pure water (Maxima Ultra Pure Water, Elga-Prima Corp, UK) with a resistivity greater than $18 \mathrm{M} \Omega / \mathrm{cm}$ was used to prepare all solutions. All chemicals were used without further purification and freshly prepared solutions were used in all experiments.

\section{Preparation of the solutions}

Chitosan was dried in an oven until a constant weight was observed. A $5 \mathrm{~g}$ of chitosan was dissolved in $500 \mathrm{~mL}$ acetic acid $(0.1 \mathrm{M})$ followed by mild stirring and heating at about $60{ }^{\circ} \mathrm{C}$ overnight to form a $10 \mathrm{~g} \mathrm{~L}^{-1}$ chitosan solution. The solution was then filtered to remove dust and other traces of impurities. Air bubbles were eliminated by keeping the solutions at room temperature for $2 \mathrm{~h}$.

A similar $10 \mathrm{~g} \mathrm{~L}^{-1}$ solution of PVA was prepared by dissolving $5 \mathrm{~g}$ in $500 \mathrm{~mL}$ preheated ultrapure water. The solution was then stirred and kept at about $80^{\circ} \mathrm{C}$ for $2 \mathrm{~h}$

\section{Preparation of the blended solutions}

Blended solutions were prepared by adding the aqueous PVA solution drop by drop to a chitosan solution, which was kept on a magnetic stirrer, at about $94{ }^{\circ} \mathrm{C}$ and the mixture was stirred at a moderate speed for $30 \mathrm{~min}$. The final composition of chitosan and PVA (CS/PVA) were varied from $90 / 10$ to $50 / 50$ by volume. Table 1 shows the designated compositions for all the solutions prepared in this study.

Table 1. Composition of the chitosan and PVA mixtures

\begin{tabular}{ccc}
\hline Solution designation & $\mathrm{V}_{\mathrm{CS}}$, vol \% & $\mathrm{V}_{\mathrm{PVA}}$, vol \% \\
\hline CS/PVA 90/10 & 90 & 10 \\
CS/PVA 80/20 & 80 & 20 \\
CS/PVA 70/30 & 70 & 30 \\
CS/PVA 60/40 & 60 & 40 \\
CS/PVA 50/50 & 50 & 50 \\
\hline
\end{tabular}

\section{Preparation of blended films}

The preparation of the blended films of CS and PVA was carried out at various proportions. The aqueous PVA solution was added drop by drop to the chitosan solution, under continuous stirring at $90{ }^{\circ} \mathrm{C}$ in various proportions by volume. The range of the added PVA to chitosan solution was varied in the range of $0-50 \mathrm{vol} \%$. Continuous stirring was performed 
for $30 \mathrm{~min}$. after mixing. Films of the yielded homogeneous solutions were obtained by casting prescribed amounts of the solution onto polystyrene Petri dishes followed by drying at $60{ }^{\circ} \mathrm{C}$ for $48 \mathrm{~h}$. The films were peeled off and stored under evacuated desiccator over fresh silica gel. All films obtained were transparent and free of air bubbles. The film thickness was measured with a digital micrometer (Mitutoyo, Japan) with $0.001 \mathrm{~mm}$ resolution. Several thickness measurements were taken at various positions on each specimen and the average value was recorded. Similar films from pure chitosan and pure PVA were prepared using the same casting procedure and used as references.

\section{Methods}

\section{Molecular weight measurements}

The molecular weight of chitosan was determined by gel permeation chromatography (GPC) according to the procedure described elsewhere ${ }^{9}$. The molecular weight was found to be $5.5 \times 10^{5} \mathrm{~g} \mathrm{~mol}^{-1}$.

\section{Mechanical properties}

The mechanical properties were measured using a universal mechanical tester (Instron, Model 5566, USA) according to the ASTM D 882-91 ${ }^{11}$. Dumbbell-shaped specimen of $50 \mathrm{~mm}$ length, $4 \mathrm{~mm}$ width and $28 \mathrm{~mm}$ neck were used. The measurements were carried out at $23{ }^{\circ} \mathrm{C}$ and $50 \%$ relative humidity. The crosshead speed was fixed at $50 \mathrm{~mm} / \mathrm{min}$. A minimum of five specimens were tested for each sample and the average was recorded.

\section{DSC measurements}

Differential scanning calorimeter (DSC) measurements were performed using a Mettler Toledo (model DSC822e). The samples were scanned under a $\mathrm{N}_{2}$ atmosphere at a constant heating rate of $10^{\circ} \mathrm{C} / \mathrm{min}$.

\section{Contact angle measurements}

The static water contact angles of the films were measured at room temperature by the drop method using an optical contact angle meter CAM 200 (KSV Instruments Ltd, Helsinki, Finland) to examine the film surface wettability. The substrates used for the experiments were glass microscope slides $(25.4 \times 76.2 \mathrm{~mm} \times 1-1.2 \mathrm{~mm})$. Each slide was cleaned before use by soaking in ethanol overnight. $7 \mu \mathrm{L}$ of distilled water was carefully injected on the film surface before measuring and the measurement time was 24 second. The contact angles were measured on both sides of the drop and averaged. Each reported contact angle was the mean value of at least 10 measurements.

\section{Results and discussion}

\section{Tensile strength and elongation \% at break}

The tensile strength (TS) and the elongation \% (E\%) at break of the CS/PVA blended films with different PVA proportions are shown in Figures 1 and 2. It was found that almost all the CS/PVA blended film recorded higher values than the pure components. The blend 90/10 recorded the highest value of TS, i.e., 58.66 MPa, after, which the TS decreased gradually as the amount of PVA increased. This shows that blending improves strength with increasing PVA content up to $40 \%$. This improvement in TS could be due to the interaction between $-\mathrm{OH}$ and $-\mathrm{NH}_{2}$ groups originated from chitosan and $-\mathrm{OH}$ groups of $\mathrm{PVA}^{12}$. It was also found that the pure PVA recorded the highest $\mathrm{E} \%$ and all the blended films recorded lower E\% than the corresponding pure components. This indicates that the blended films 
were more brittle and less flexible than the pure components. Similar behavior was reported in the literature for chitosan associated with PVA. For example, Park et al ${ }^{13}$ reported that PVA/CS blended film cast from acetic acid recorded higher values of TS and lower E\% than the pure polymers. Hyder and $\mathrm{Chen}^{14}$ and Bahrami et al ${ }^{15}$ also reported similar behavior of PVA/CS blended films with respect to TS.

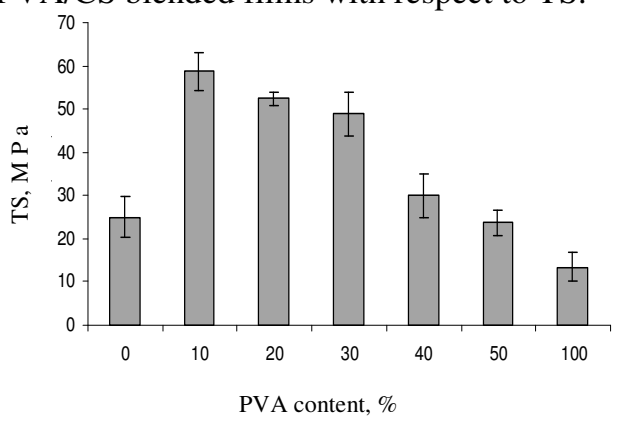

Figure 1. Tensile strength of chitosan/PVA blended films

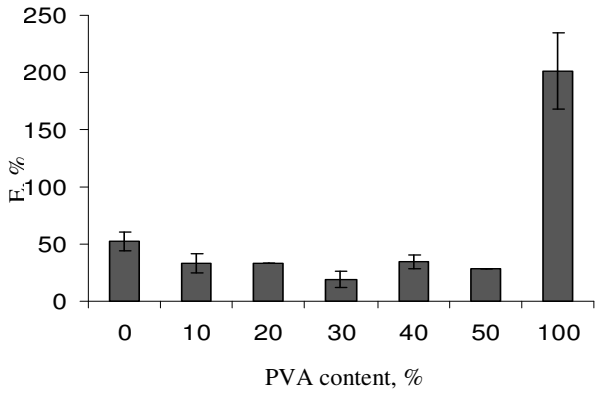

Figure 2. Elongation $\%$ of chitosan/PVA blended films

\section{Thermal properties}

Figure 3 shows the DSC curves of the blended CS/PVA films together with their pure CS and PVA components. As can be seen, DSC curve of chitosan film shows a broad endothermic peak at about $79{ }^{\circ} \mathrm{C}$ while PVA film shows a smaller endothermic peak at $\sim 89{ }^{\circ} \mathrm{C}$. All compositions exhibited broad endothermic peaks at lower positions than the pure components in the range of 70.3 to $77.3{ }^{\circ} \mathrm{C}$ (Table 2). This endothermic peak, often termed as dehydration temperature $\left(T_{\mathrm{D}}\right)$, is due to the evaporation of water associated with the hydrophilic groups of the polymers ${ }^{16}$ and responsible for the strength of water-polymer interaction ${ }^{17}$.

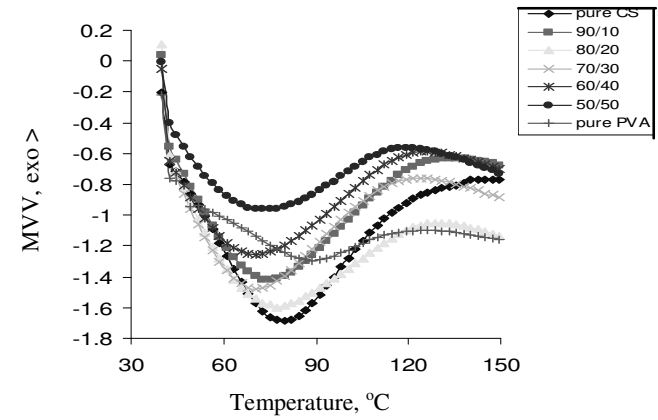

Figure 3. The DSC first run curves of CS/PVA blended films

The $T_{\mathrm{D}}$ of chitosan film obtained is in close agreement with previous studies ${ }^{18,19}$. The presence of $T_{\mathrm{D}}$ suggests that some bound water was still not removed from the samples after drying. A closer look at Figure 3 reveals that there is a difference in the endothermic peak area of all films, i.e., they vary in their water-holding capacity in a way showing that pure chitosan film has the highest water content while pure PVA one has the lowest water content unlike the blend films which their $\mathrm{T}_{\mathrm{D}}$ shows lower values and stands in between those of their pure components and is a function of the composition. The variation in $\mathrm{T}_{\mathrm{D}}$ of blended film is believed to be due to the physical and molecular changes caused by the molecular chains interaction between chitosan and PVA, which suggests the formation of more stable films 
Since chitosan tends to absorb moisture, a second heating run of the DSC, after heating to $150{ }^{\circ} \mathrm{C}$, hold for a minute and then cooling to $40{ }^{\circ} \mathrm{C}$, was performed to eliminate the effect of moisture (Figure 4). The first point to note is the absence of the endothermic peak, confirmed that this peak is attributed to the water content in the sample. Also, pure PVA film exhibited a sharp endothermic melting transition at about $222{ }^{\circ} \mathrm{C}$ (Table 2) while pure chitosan film did not show any melting transition due to the fact that most polysaccharides do not melt but degrade upon heating above a certain temperature. The melting point of PVA is close to the value reported in the literature. For example, Yang et al. ${ }^{20}$ reported a melting endothermic peak at $223{ }^{\circ} \mathrm{C}$ which is very close to the value reported in this study $\left(222^{\circ} \mathrm{C}\right)$ while Shi et $a l^{21}$ demonstrated that pure PVA film exhibits a melting temperature at $230{ }^{\circ} \mathrm{C}$. Also, Yang et al. ${ }^{22}$ reported a melting point of PVA hydrogel at $228.3{ }^{\circ} \mathrm{C}$. In this work, smaller peaks of melting transition at different temperatures appeared in the DSC curves of CS/PVA blend films with various blend ratios from 90/10 to 50/50 at temperature range of $214.9-217.3{ }^{\circ} \mathrm{C}$. This shows that there is a little shift in the endothermic melting transition to lower temperature with increasing chitosan content in the blends. The melting depression in CS/PVA blends may be due to some interaction between the two polymers.

\section{Contact angle measurements}

Figure 5 shows the static water contact angle versus the PVA content. A general decrease in the static water contact angle with increasing PVA content in the blend is observed i.e., there is an increase in the wettability with increasing the PVA concentration in the blend.

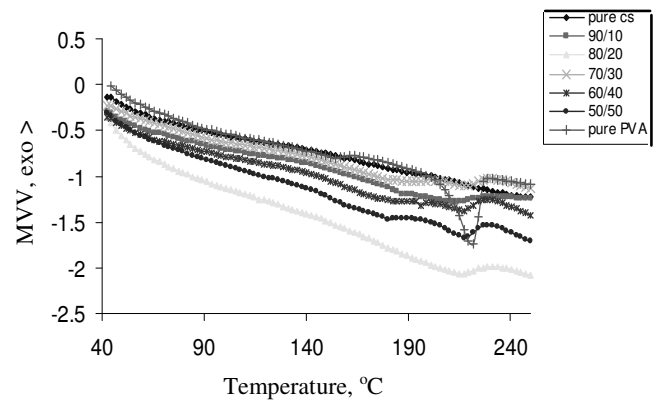

Figure 4. The DSC second run curves of CS/PVA blended films

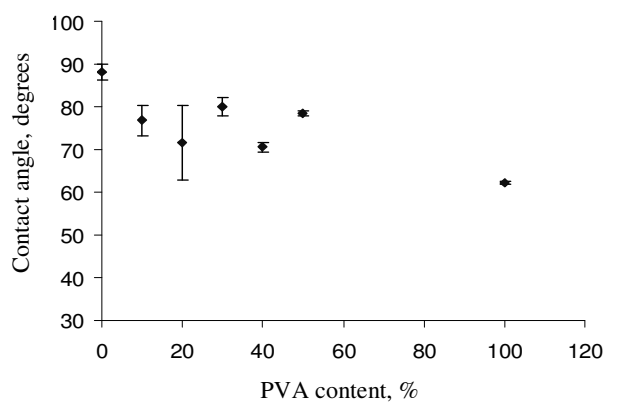

Figure 5. The relationship between the water-contact angle and the PVA content

Table 2. The thermal properties of CS/PVA blended films with different PVA content

\begin{tabular}{cccccccc}
\hline Blend composition CS/PVA & $100 / 0$ & $90 / 10$ & $80 / 20$ & $70 / 30$ & $60 / 40$ & $50 / 50$ & $0 / 100$ \\
\hline $\mathrm{T}_{\mathrm{D}}$ (first run) & 79.0 & 75.0 & 77.3 & 70.3 & 70.3 & 72.6 & 89.0 \\
$\mathrm{~T}_{\mathrm{m}}$ (second run) & $\mathrm{ND}$ & 214.9 & 214.9 & 217.3 & 217.3 & 217.3 & 221.9 \\
\hline \multicolumn{7}{c}{ ND not detected }
\end{tabular}

The contact angle of pure CS was $88.12^{\circ} \pm 1.91$, which agrees well with the literature ${ }^{23,24}$ while the contact angle of the blended films ranged from about $70.47^{\circ} \pm 0.96$ to $80.02^{\circ} \pm 2.27$. In general, the contact angles for all the blended films were less than $90^{\circ}$, indicating good hydrophilicity of the surfaces of the obtained films.

\section{Conclusion}

Blended films of chitosan/polyvinyl alcohol (CS/PVA) were prepared at various proportions. Investigations of the obtained blended films were carried out with mechanical, DSC and contact angle measurements. Results obtained from the mechanical and thermal 
stability studies revealed that interaction between chitosan and PVA was achieved. In addition, the water contact angle measurements showed an increase in the hydrophilicity of the blended films suggesting that the blending of chitosan with PVA improved the surface wettability of the blended films.

\section{Acknowledgment}

The authors are grateful to University of Malaya for supporting this research project under the research grant, PS188/2008A.

\section{References}

1. Taravel M N and Domard A, Biomaterials, 1996, 17(4), 451-455.

2 Mucha M, React Funct Polym., 1998, 38, 19.

3. Srinivasa P C, Ramesh M N, Kumar K R and Tharanathan R N, Carbohydr Polym., 2003, 53(4), 431-438.

4. Shanmugasundaram N, Ravichandran P, Neelakanta P R, Nalini R, Subrata P and Rao K P, Biomaterials, 2001, 22, 1943.

5. Chen X G, Wang Z, Liu W S and Park H J, Biomaterials, 2002, 23(23), 4609-4614.

6. Sionkowska A, Wisniewski M, Skopinska J, Kennedy C J and Wess T J, Biomaterials, 2004, 25(5), 795-801.

7. $\quad$ Engelberg I and Kohn J, Biomaterials, 1991, 12, 292-304.

8. El-hefian E A, Nasef M M and Yahaya A,. E-J Chem., 2010, 7(4), 1212-1219.

9. $\quad$ El-hefian E A, Nasef M M and Yahaya A H, E- J Chem., 2010, 7(S1), S349-S357.

10. Muzzarelli R A A and Rochetti R, Carbohydr Polym., 1985, 5, 461-472.

11. ASTM, Standard test methods for tensile properties of thin plastic sheeting (D 88291), In annual book of ASTM standards, American Society for Testing and Materials, Philadelphia, 1995.

12. Kim J H, Kim J Y, Lee Y M and Kim K Y, J Appl Polym Sci., 1992, 45. 1711.

13. Park S Y, Jun S T and Marsh K S, Food Hydrocol., 2001, 15, 499-502.

14. Hyder M N and Chen P, J Membr Sci., 2009, 340(1-2), 171-80.

15. Bahrami S B, Kordestani S S, Mirzadeh H and Mansoori P, Iran Polym J., 2003, 12, 139-146.

16. Cheung M K, Wan K P Y and Yu P H, J Appl Polym Sci., 2002, 86, 1253-1258.

17. Kittur F S, Prashanth K V H, Sankar K U and Tharanathan R N, Carbohydr Polym., 2002, 49, 185.

18. Lima C G A, De Oliveira R S, Figueiro S D, Wehmann C F, Goes Sombra J C and Ombra A S B, Mater Chem Phys., 2006, 99, 284.

19. Wang Y C, Lin M, Wang D and Hsieh H, Biomaterials, 2003, 24, 1047.

20. Yang J M, Su W Y, Leu T L and Yang M C, J Membr Sci., 2004, 236, 39-51.

21. Shi R, Bi J, Zhang Z, Zhu A, Chen D, Zhou X, Zhang L and Tian W, Carbohydr Polym., 2008, 74(4), 763-770.

22. Yang X, Zhu Z, Liu Q, Chen X and Ma M, Radiat Phys Chem., 2008, 77, 954-960.

23. Tangpasuthadol V, Pongchaisirikul N and Hoven V P, Carbohydr Res., 2003, 338(9), 937-942.

24. De Britto D and Assis O B G, Carbohydr Polym., 2007, 69(2), 305-310. 


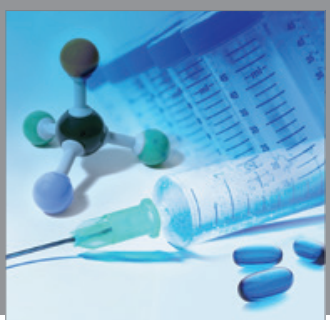

International Journal of

Medicinal Chemistry

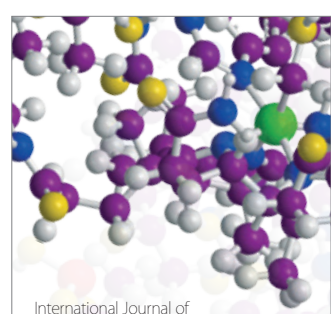

Carbohydrate Chemistry

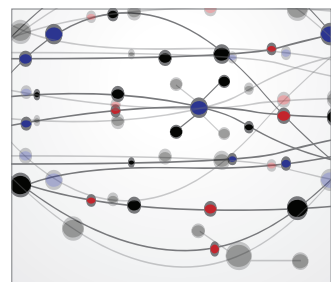

The Scientific World Journal
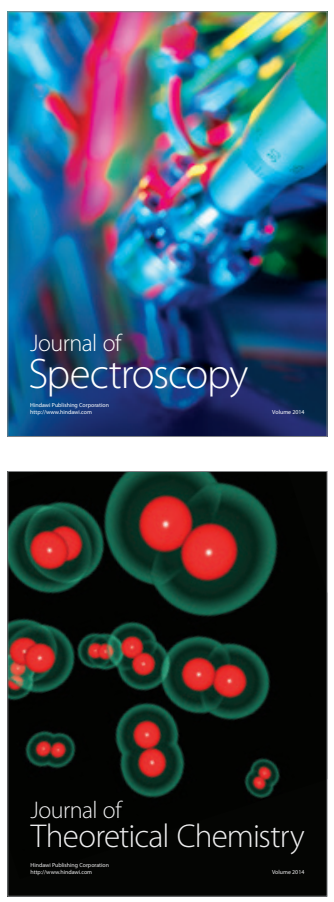
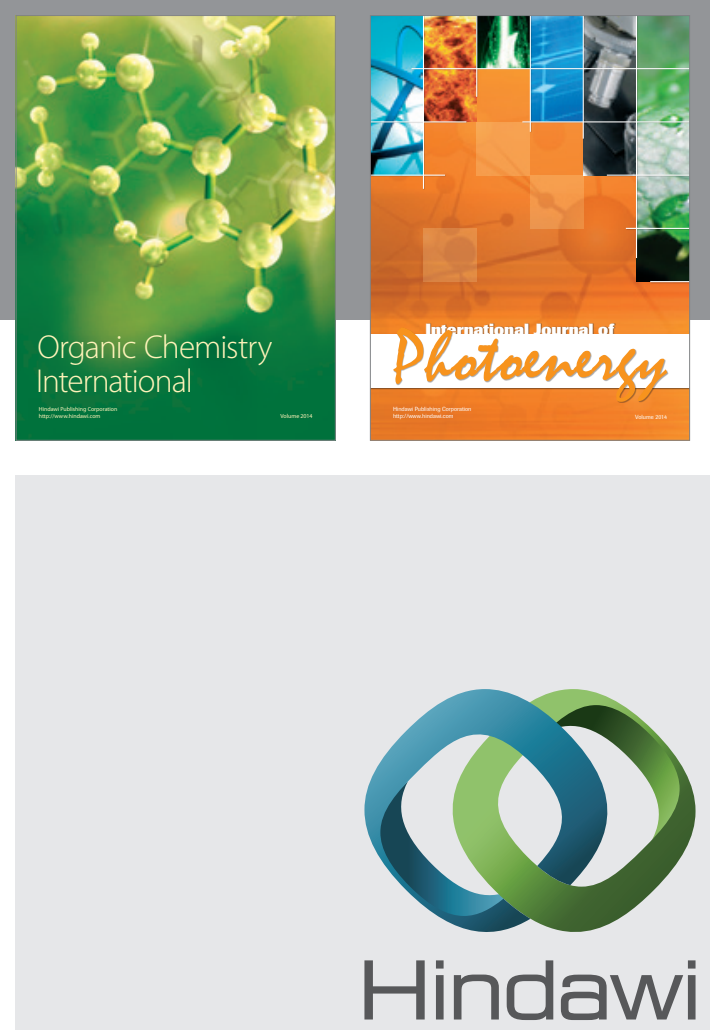

Submit your manuscripts at

http://www.hindawi.com
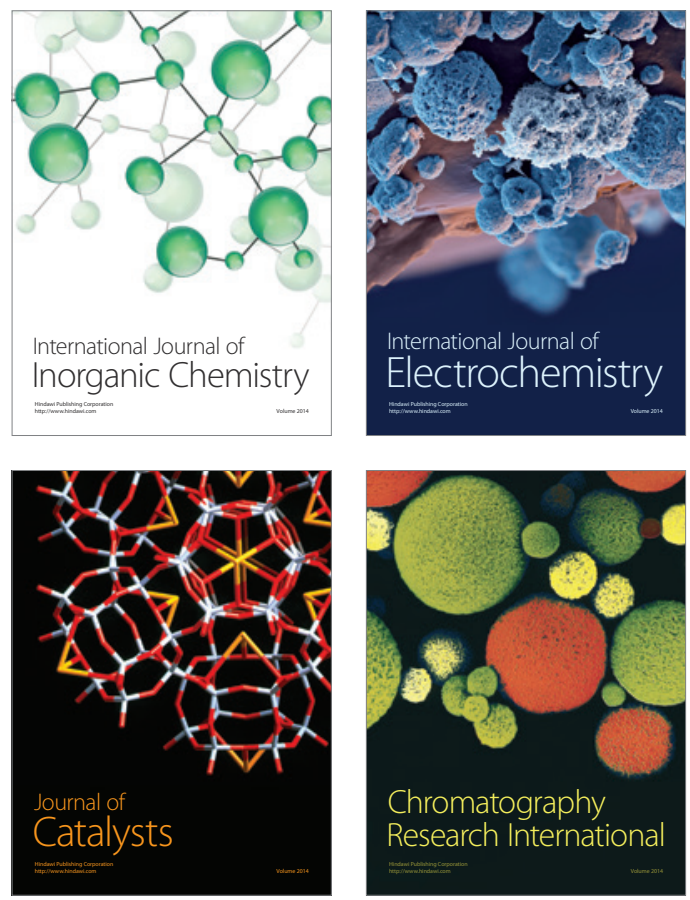
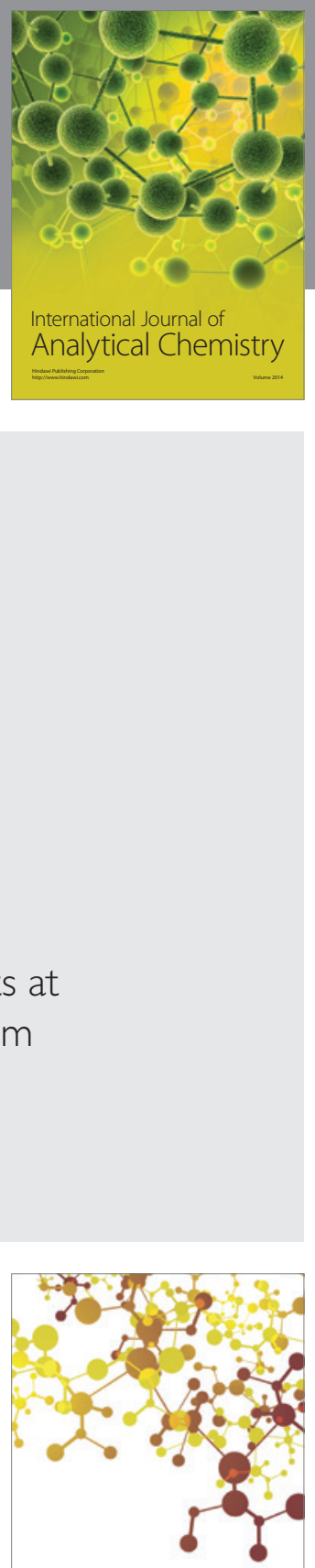

Journal of

Applied Chemistry
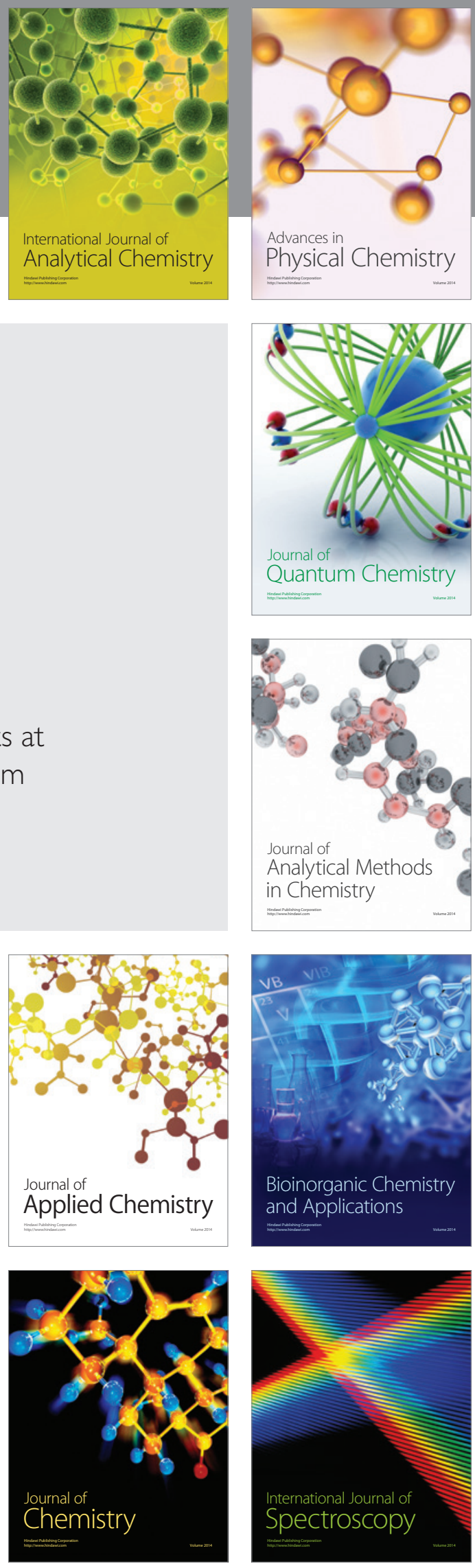